\title{
Biomassa e teor de óleo essencial em Aloysia triphylla (l'hérit) Britton submetida a diferentes níveis de reposição hídrica e à variação sazonal das condições ambientais
}

SCHWERZ, L.1*; CARON, B.O.'; MANFRON, P.A.'; SCHMIDT, D.'; ELLI, E. F.1

${ }^{1}$ Departamento de Ciências Agronômicas e ambientais, Universidade Federal de Santa Maria (UFSM), Linha Sete de Setembro s/n, BR386 Km40, CEP 98400-000, Frederico Westphalen (RS), Brasil. *Autor para correspondência: luagronomia@hotmail.com

RESUMO: A variação nos elementos meteorológicos ao longo do ano, configurando as quatro estações, proporciona diferentes condições de crescimento e desenvolvimento das plantas, alterando o metabolismo e a constituição dos tecidos vegetais. Assim, o presente trabalho teve o objetivo de determinar a influência da sazonalidade em parâmetros fenométricos e na produção de óleo essencial em Aloysia triphylla (L'Hérit) Britton, submetida a diferentes níveis de reposição hídrica cultivada em ambiente protegido. As avaliações foram realizadas no dia que marcou a metade de cada estação do ano (verão, outono, inverno e primavera), sendo coletado todo o material vegetativo $20 \mathrm{~cm}$ acima do solo. A reposição hídrica foi baseada na evapotranspiração de referência (ETo) para o ambiente externo em função dos dados de entrada da equação de Penman-Monteith a qual apresenta parametrizações para dados obtidos em estações meteorológicas em padrões oficiais, sendo assim aplicados 125, 100, 75 e 50\% da ETo em turno de rega de dois dias. A produção de massa fresca, seca e de parte aérea, bem como a área foliar, apresentaram maiores valores na estação primavera, sendo o inverno e o verão responsáveis pelos menores valores. O maior teor de óleo essencial foi observado nas estações de menor produção de biomassa, ou seja, verão e inverno. A reposição hídrica que proporcionou maior produção de material vegetativo foi a de $125 \%$ da ETo; no entanto, o maior teor de óleo foi observado nas menores reposições hídricas (75 e 50 \% da ETo, respectivamente). A produção de óleo foi maior na primavera, a qual não sofreu influência da reposição hídrica ao longo do ano.

Palavras-chave: Planta medicinal, sazonalidade, déficit hídrico, óleo essencial.

\begin{abstract}
Biomass and essential oil content in Aloysia triphylla (L'Herit) Britton subjected to different levels of water reposition and season alchanges of environmental conditions. The variation in weather elements throughout the year, setting the four seasons, provides different conditions for growth and development of plants, altering the metabolism and the structure of plants' tissues. This study aimed to determine the influence of seasonality on fenometrics parameters and on the oil production in Aloysia triphylla (L'Herit) Britton, subjected to different levels of water availability cultivated in greenhouse conditions. The evaluations were made on the day that marked the middle of each season (summer, autumn, winter and spring), and all plant material were collected $20 \mathrm{~cm}$ above ground. The water reposition was based on the evapotranspiration reference (ETo) to the external environment being applied 125, 100, 75 and $50 \%$ of ETo in an irrigation interval of two days. The production of fresh, dry and aerial part mass, as well as leaf areamass, showed higher values in the spring season, while winter and summer were responsible for lower values. The highest content of essential oil was observed at seasons with lower biomass production. The water availability that provided higher production of plant material was the one with $125 \%$ of ETo, however, the highest oil content was observed at lower water availability ( $75 \%$ and $50 \%$ of ETo, respectively). The oil production was higher in the spring and was not affected throughout the year by the water availability.
\end{abstract}

Keywords: Medicinal plant, Seasons, Drought, Yield. 


\section{INTRODUÇÃO}

Os avanços tecnológicos alcançados nos últimos dois séculos tornaram possíveis a identificação de centenas de compostos químicos vegetais e a elucidação científica dos efeitos terapêuticos de plantas consagradas pelo conhecimento popular. A Aloysia triphylla (L'Hérit) Britton (Verbenaceae), popularmente, conhecida como cidrão e erva Luiza, é uma planta que apresenta folhas de grande importância medicinal, devia a presença de compostos químicos, empregados no combate a resfriados febris, além de ser antiespasmódica, eupéptica, estimulante, calmante e tônica (Paulus et al., 2013), sendo também usada para tratamento contra afecções do coração, histeria e melancolia (Lorenzi \& Matos, 2008).

Uma das principais limitações no cultivo de plantas medicinais é referente ao teor de constituintes químicos de importância medicinal, ou seja, os ingredientes ativos (i.a.), os quais podem variar em função das condições ambientais, tais como a temperatura, radiação solar, umidade, déficit de pressão de vapor na atmosfera (DPV) e disponibilidade hídrica (Rodrigues-Das-Dores \& Casali, 2007).

As variações temporais e espaciais no conteúdo total de metabólitos secundários em plantas, bem como suas proporções relativas, ocorrem em diferentes níveis, tais como sazonais e diárias. Apesar da existência de um controle genético, a expressão gênica pode sofrer modificações resultantes da interação de processos bioquímicos, fisiológicos, ecológicos e evolutivos (Lindroth et al., 1987; Hartmann, 1996). Os metabólitos secundários representam uma interface química entre as plantas e o ambiente circundante, portanto, sua síntese é frequentemente afetada por condições ambientais (Kutchan, 2001).

A sazonalidade exerce grande impacto no crescimento, desenvolvimento e no teor de princípios ativos das plantas, isso devido à combinação dos fatores ambientais que ocorrem de maneira diversificada ao longo das quatro estações do ano (Pinto \& Bertolucci, 2002). Esta dependência do ambiente é destacada por Silva (2005), a mesma ressalta que a época em que se obtém maior produção de óleo essencial, pode não ser a época de maior produção do composto químico de interesse e também de acúmulo de fitomassa nas plantas.

Dentre as variações no ambiente, a disponibilidade hídrica é considerada o fator climático de maior impacto sobre a produtividade agrícola, sendo o fator que rege a distribuição das espécies nas diferentes zonas climáticas do globo (Turner \& Jones, 1980; Kramer \& Boyer, 1995).
Trabalhos recentes apontam a necessidade de melhor compreender a influência da disponibilidade de água às plantas medicinais, tendo em vista que o objetivo de seu cultivo está associado à produção de compostos secundários de interesse comercial (Alvarenga et al., 2012).

Em trabalho realizado por Meira et al. (2011) na espécie medicinal Melissa officinalis concluiu-se que a melhor disponibilidade hídrica para o crescimento não foi a mesma que para produção de óleo essencial, sendo a produção de óleo reduzida sob irrigação plena. A redução na disponibilidade hídrica pode acarretar em estresse, e consequentemente desencadear um processo pelo qual o carbono fixado fotossinteticamente para a síntese de metabólitos primários é redirecionado para a síntese de metabólitos secundários como os compostos fenólicos e terpenóides (Abreu \& Mazzafera, 2005). Assim, a deficiência hídrica moderada, muitas vezes, tem se mostrado positiva no acúmulo de substâncias bioativas em espécies medicinais, aromáticas e condimentares (Pravuschi et al. 2010).

Com base no exposto acima, o presente trabalho teve como objetivo avaliar o desempenho de Aloysia triphylla submetida a diferentes níveis de disponibilidade hídrica, quanto a componentes fenométricos e teor e produção de óleo essencial, ao longo das quatro estações do ano.

\section{MATERIAL E MÉTODOS}

O experimento foi desenvolvido na área pertencente ao Laboratório de Agroclimatologia (LAGRO) vinculado à Universidade Federal de Santa Maria Campus de Frederico Westphalen - RS em ambiente protegido, com localização geográfica de $27^{\circ} 23^{\prime} 48^{\prime} \mathrm{S}, 53^{\circ} 25^{\prime} 45^{\prime \prime} \mathrm{W}$ e altitude de $490 \mathrm{~m}$. Nas Tabelas 1 e 2 estão descritas as características físicas e químicas do solo da área experimental, sendo o mesmo classificado como Latossolo Vermelho aluminoférrico típico (EMBRAPA, 2006). Segundo a classificação climática de Köppen, o clima da região é Cfa (Maluf, 2000).

O ambiente no qual foi realizado o presente trabalho é caracterizado por apresentar cobertura com filme plástico de 150 micras, com um pé direito de $3,5 \mathrm{~m}$ de altura e dimensões de dez metros de largura e vinte de comprimento, sendo o manejo das cortinas realizado diariamente com a finalidade de reduzir a amplitude térmica, a circulação de ventos fortes e a entrada de água advinda de chuvas. No interior da mesma instalou-se uma estação meteorológica compacta modelo ISIS S1220 da Squiter do Brasil, com a finalidade de caracterizar o ambiente no qual se deu a condução do experimento, 
TABELA 1. Caracterização física do solo da área experimental. Frederico Westphalen - RS, 2012.

\begin{tabular}{|c|c|c|c|c|}
\hline \multirow{2}{*}{ Profundidade } & \multicolumn{3}{|c|}{ Teor \% } & \multirow[t]{2}{*}{ Tipo de solo } \\
\hline & Areia & Silte & Argila & \\
\hline $0-50$ & 23,2 & 28,5 & 48,3 & $3^{*}$ \\
\hline
\end{tabular}

${ }^{*}$ Instrução normativa N²/2008 (MAPA)

TABELA 2. Caracterização química do solo da unidade experimental. Frederico Westphalen - RS, 2012.

\begin{tabular}{|c|c|c|c|c|c|c|c|c|c|c|c|}
\hline $\mathrm{pH}$ & Índice SMP & $\mathrm{P}$ & $\mathrm{K}$ & M.O. & $\mathrm{Al}$ & $\mathrm{Ca}$ & $\mathrm{Mg}$ & CTC & $\mathrm{H}+\mathrm{Al}$ & \multicolumn{2}{|c|}{ \% Sat. da CTC } \\
\hline & & $\mathrm{ms}$ & & $\%$ & $\mathrm{cmolc} / \mathrm{L}$ & & & & & Bases & $\mathrm{Al}$ \\
\hline 5,7 & 6,1 & 5, & 128,5 & 3,9 & 0,0 & 12,5 & 4,8 & 20,9 & 3,3 & 84,2 & 0,0 \\
\hline
\end{tabular}

tais como a umidade e a temperatura do ar.

O delineamento experimental utilizado foi o de blocos ao acaso em um esquema fatorial $4 \times 4$ com quatro repetições, sendo os tratamentos compostos por quatro níveis de reposição hídrica $(50,75,100$ e $125 \%$ da evapotranspiração de referência - ETo) e quatro estações do ano (verão, outono, inverno e primavera).

O efeito da sazonalidade foi mensurado a partir das coletas de todo material vegetativo das plantas, as quais foram realizadas exatamente nos dias que marcaram a metade de cada estação do ano, sendo no verão dia $05 / 02 / 2012$, outono dia $06 / 05 / 2012$, inverno dia 06/08/2012 e primavera dia 06/11/2012.

Os níveis de reposição hídrica aplicados no presente trabalho foram de 50, 75, 100 e 125\% da evapotranspiração de referência ETo ( $\mathrm{mm}^{\left.-\mathrm{dia}^{-1}\right)}$ calculada para o ambiente externo e determinada pelo método de Penman-Monteith, descrito no boletim "Estudo FAO Irrigação e Drenagem 56" (Allen et al., 1998), sendo o total de cada estação e a média diária apresentados na Tabela 3. Para tal, as variáveis meteorológicas utilizadas foram temperatura, umidade relativa do ar, radiação global incidente e velocidade do vento, obtidas em escala diária junto à estação meteorológica automática da rede do INMET, localizada a aproximadamente 300 metros do experimento.

A implantação ocorreu diretamente no solo, sendo os tratamentos isolados por 2 fileiras de cultivo da mesma espécie, as quais receberam a mesma lâmina de irrigação do tratamento em questão. As unidades experimentais foram compostas por duas plantas de Aloysia triphylla, espaçadas em 0,8m entre plantas e $1 \mathrm{~m}$ nas entre linhas, totalizando 8 plantas de avaliação em parcelas com dimensões de $8 \times 3$ metros. As mudas foram produzidas a partir de estaquia de material vegetativo obtido na cidade de Curitiba-PR com aplicação de ácido indol-butírico na concentração de $1000 \mathrm{mg} \mathrm{L}^{-1}$ de solução, na qual as estacas permaneceram por 15 minutos, objetivando-se rápido enraizamento. As mesmas foram transplantas para a estufa no dia 03 de novembro de 2011 com revolvimento prévio do solo, em função dos níveis de fertilidade não foi realizada adubação. A irrigação foi realizada com auxílio de regadores e com turno de rega fixado em dois dias.

TABELA 3. Nível de reposição hídrica total e diário $(\mathrm{mm}$. dia-1-1), nas respectivas disponibilidades hídricas ao longo das quatro estações do ano. Frederico Westphalen - RS, 2012.

\begin{tabular}{llllll}
\hline \multirow{2}{*}{ Estação } & \multicolumn{5}{l}{ Reposição hídrica (\% ETo) } \\
\hline \multirow{2}{*}{ Verão } & 125 & 100 & 75 & 50 \\
& Total & 550.32 & 448.25 & 346.19 & 244.13 \\
Outono & $\mathrm{mm} \cdot$ dia-1 $^{-1}$ & 7.56 & 6.16 & 4.76 & 3.35 \\
& Total & 458.64 & 366.91 & 275.18 & 183.45 \\
Inverno & $\mathrm{mm}$. dia-1 & 6.30 & 5.04 & 3.78 & 2.52 \\
& Total & 235.80 & 188.64 & 141.48 & 94.32 \\
Primavera & $\mathrm{mm} \cdot$ dia-1 $^{-1}$ & 3.24 & 2.59 & 1.94 & 1.30 \\
& Total & 375.30 & 300.24 & 225.18 & 150.12 \\
\hline
\end{tabular}

Rev. Bras. PI. Med., Campinas, v.17, n.4, p.631-641, 2015. 
As variáveis analisadas foram: área foliar ( $A F-\mathrm{cm}^{2}$. planta-1), índice de área foliar (IAF), massa seca e fresca de ramos (MSR e MFR - g. planta-1 $^{-1}$ e total (MST e MFT - g. planta-1), medida indireta de clorofila (índice SPAD), altura de planta (AP $-\mathrm{cm}$ ), teor de óleo (TEOR - \%) e produtividade de óleo (Kg. ha-1).

A área foliar foi determinada com auxílio de um integrador de área foliar marca LICOR modelo LI-3000C e é expresso em $\mathrm{cm}^{2}$. planta-1, e o índice de área foliar, como sendo a relação entre área foliar e o espaço ocupado pela planta no solo, expresso em $\mathrm{m}^{2} \cdot \mathrm{m}^{-2}$. As massas fresca e seca de folhas e ramos foram determinadas através da coleta de todo material vegetativo de 8 plantas por tratamento, sendo realizado sempre a média em cada unidade experimental. Após a aferição da massa fresca, destinou-se parte da massa de folhas e ramos para determinação do teor de umidade do material em estufa de circulação de ar forçada a $60^{\circ}$ por 72 horas, após procedeu-se a correção dos valores para massa seca.

A medida indireta da clorofila foi realizada com o emprego de um medidor portátil de clorofila (SPAD-502), equipamento que permite medições instantâneas do teor de clorofila na folha por meio do índice SPAD (Minolta, 1989). A altura de planta foi determinada com auxílio de uma régua graduada, sendo este expresso em $\mathrm{cm}$.

Para a determinação do teor de óleo essencial, procedeu-se a extração do óleo pelo método de hidrodestilação em aparelho de Clevenger. $\mathrm{O}$ material vegetal foi colocado em balão volumétrico de $5.000 \mathrm{~mL}$ e acrescentado um volume de $2500 \mathrm{~mL}$ de água destilada. A quantidade de material vegetativo utilizada variou em razão da produção de cada estação do ano, assim para o verão utilizou-se 100,150 no outono, 150 no inverno e 200 gramas de massa fresca de folhas na primavera.

O material foliar era coletado sempre no início da manhã e previamente picado com tesouras, sendo logo em seguida direcionado para a extração do óleo essencial. Após a detecção de início de fervura, cronometrou-se o tempo de três horas. Findo o período de extração, o hidrolato obtido foi pesado, para determinação do teor e armazenado em recipientes de vidro de $2 \mathrm{~mL}$, devidamente lacrados e cobertos por papel laminado, para evitar a fotodegradação de moléculas. Ao término deste procedimento as amostras foram estocadas em um ultra freezer a uma temperatura próxima a $-20^{\circ} \mathrm{C}$.

O teor de óleo foi obtido pela seguinte expressão:

$$
T \%=\frac{\text { Massa do óleo }(g)}{\text { Massa fresca de folhas }(g)} \times 100
$$

A produtividade foi obtida extrapolando-se a produção de óleo por planta em $0,8 \mathrm{~m}^{2}$ para hectare (12.500 plantas), pela expressão:

(Kg) $\times 12.500$

PROD (Kg. ha-1) $=$ Massa de óleo. planta-1

Os resultados foram submetidos à análise da variância através do Software "Statistical Analysis System" (SAS LEARNING EDITION, 2003). Para os parâmetros em que se rejeitou a hipótese de igualdade a $5 \%$ de probabilidade de erro procederam-se a análise de regressão para o fator disponibilidade hídrica e teste de Tukey para o fator sazonalidade.

\section{RESULTADO E DISCUSSÃO}

Nas Figuras 1, 2 e 3 são demonstradas as variáveis meteorológicas que caracterizaram o interior do ambiente protegido, sendo temperatura do ar (Figura 1), umidade relativa do ar (Figura 2) e radiação solar global incidente (Figura 3 ) no interior da estufa. Assim, são observados valores de temperatura média do ar ( $\mathrm{T}^{\circ}$ ar) na ordem de 21,$9 ; 21,6 ; 16,9$ e $19,6^{\circ} \mathrm{C}$ para as coletas de verão, outono, inverno e primavera respectivamente, sendo o verão responsável pelo maior valor e o inverno pelo menor valor de $\mathrm{T}^{\circ}$ ar.

A Umidade relativa do ar (UR \%) no interior da estufa apresentouvalores na ordem de 68,2; 70,5; 79,7 e 71,9 \% para as estações verão, outono, inverno e primavera, respectivamente, sendo o inverno responsável pelo maior valor e o verão pelo menor valor de UR. O fluxo médio de radiação solar global incidente $(\mathrm{Rg})$ em escala diária no interior da estufa foi 18,$46 ; 14,27 ; 7,77$ e $11,88 \mathrm{MJ} \mathrm{m}^{-2}$. dia-1 nas respectivas estações do ano verão, outono, inverno e primavera, sendo o verão responsável pelo maior valor e o inverno pelo menor valor de $\mathrm{Rg}$.

A partir do resumo da análise de variância (Tabela 4) é possível identificar uma alta relação entre as variáveis biométricas analisadas e as condições ambientais prevalecentes em cada estação. Assim, para o fator sazonalidade todas variáveis apresentaram diferenças significativas entre as estações do ano, ao passo que para o fator disponibilidade hídrica apenas a MFR, MSR e a PROD não foram significativamente influenciadas. Ainda, é observada uma interação entre os fatores estudados, sendo a mesma significativa para as variáveis AF, IAF e TEOR.

O efeito da sazonalidade sobre as variáveis estudadas é apresentado na Tabela 5, sendo a estação primavera responsável pelos maiores valores de AF, IAF, MFF, MSF, MFT, MST, AP e PROD, superando a média geral das estações em 117,17; 117,17; 63,91; 63,93; 45,21; 44,39; 49,77 e $29,84 \%$, respectivamente. As estações de

Rev. Bras. PI. Med., Campinas, v.17, n.4, p.631-641, 2015. 


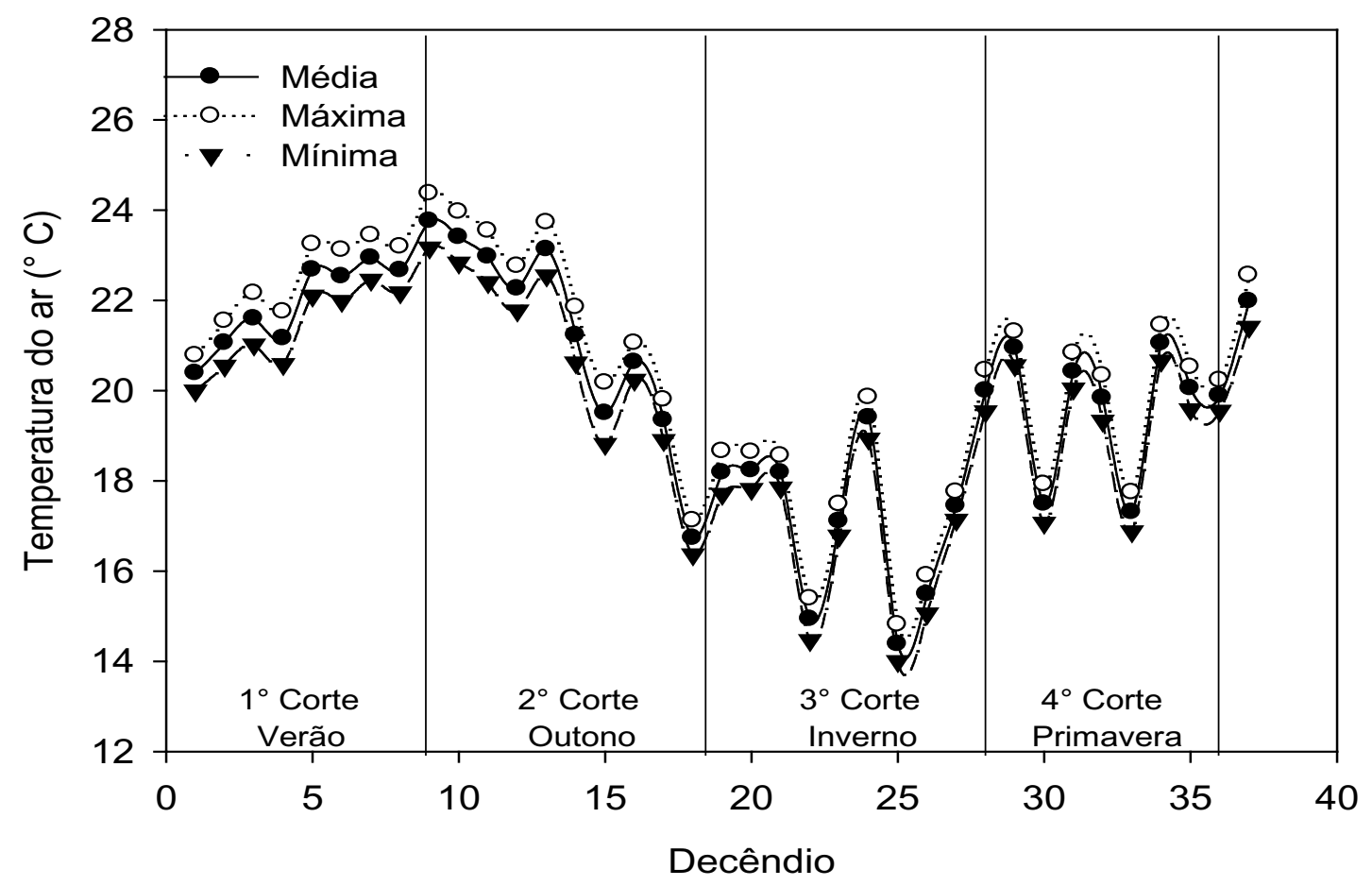

FIGURA 1. Temperatura média, máxima e mínima $\left({ }^{\circ} \mathrm{C}\right)$ no interior da estufa plástica. Frederico Westphalen RS, 2012.

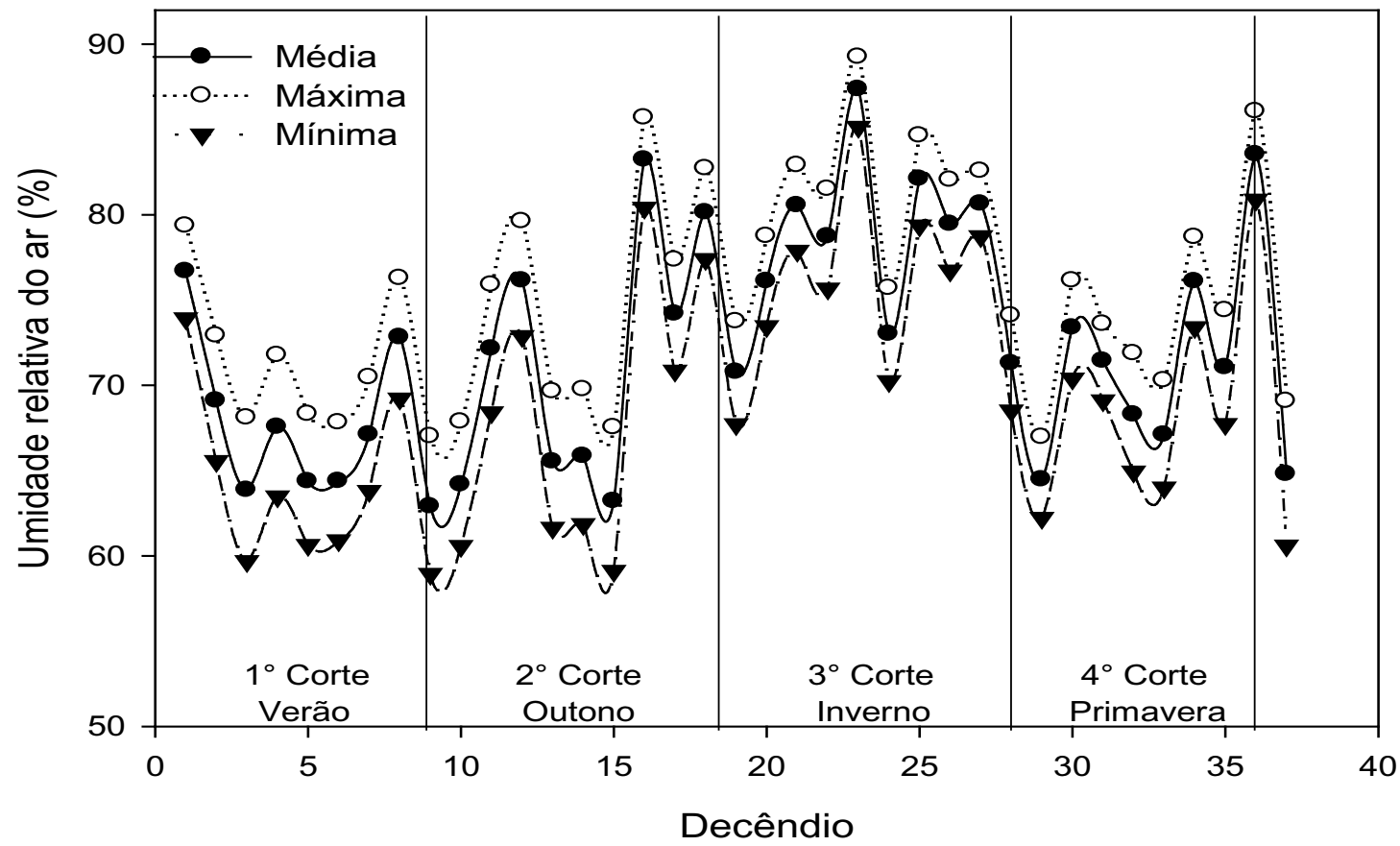

FIGURA 2. Umidade relativa do ar média, mínima e máxima no interior da estufa plástica. Frederico Westphalen - RS, 2012.

inverno e verão apresentaram os menores valores, destacando-se o inverno com percentuais de 52,11; 52,$11 ; 47,81 ; 47,83 ; 57,91 ; 57,89 ; 51,94 ; 52,11$ e $29,96 \%$ abaixo da média para as variáveis $A F$, IAF, MFF, MSF, MFR, MSR, MFT, MST, e PROD respectivamente.
Tanto a área foliar como o índice de área foliar foram superiores na primavera associado à reposição hídrica de $125 \%$ da ETo (Tabela 6), ao passo que no inverno observou-se o menor valor associado aos menores valores na referida reposição, não diferenciando do verão e do outono 


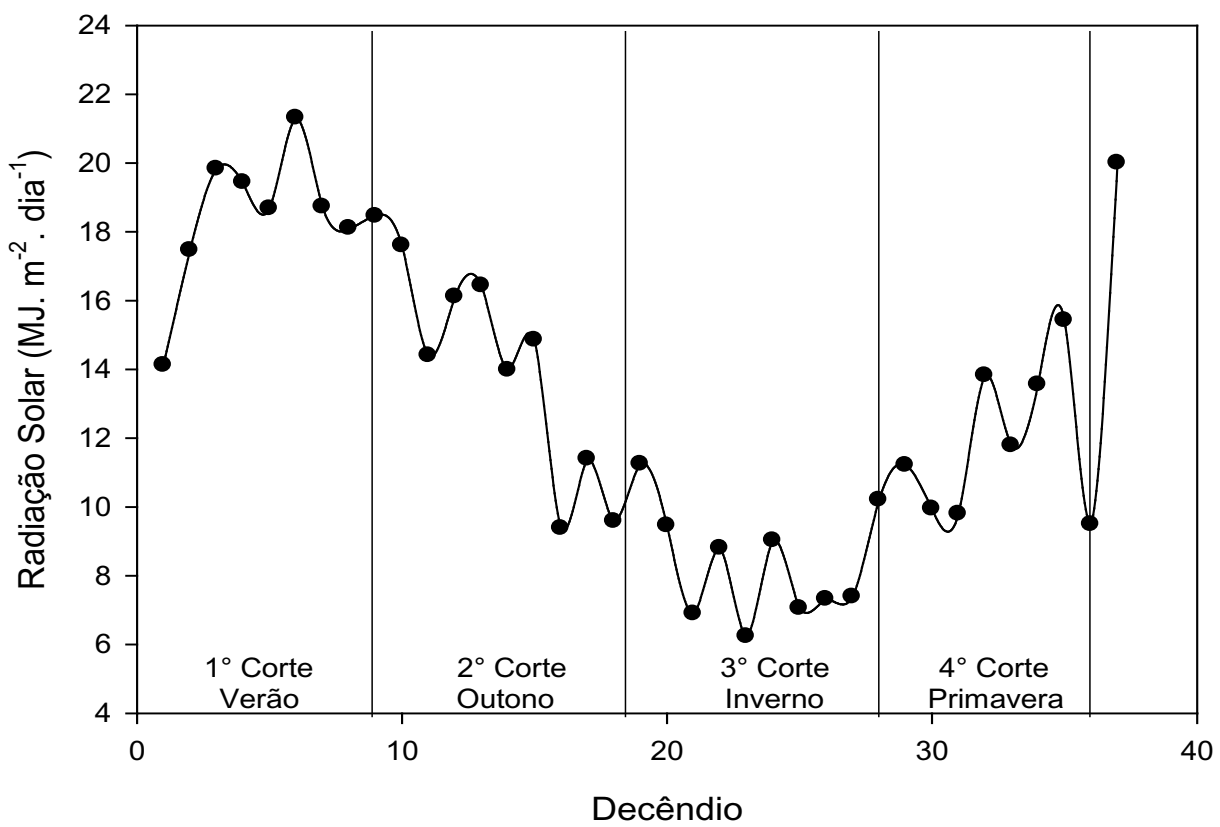

FIGURA 3. Radiação solar global incidente no interiro da estufa plástica. Frederico Westphalen - RS, 2012.

TABELA 4. Resumo da análise de variância para os parâmetros, área foliar ( $\mathrm{AF}-\mathrm{cm}^{2}$. planta-1), índice de área foliar (IAF $-\mathrm{m}^{2} \cdot \mathrm{m}^{-2}$ ), massa seca e fresca de folhas (MSF e MFF - g. planta-1), massa seca e fresca de ramos

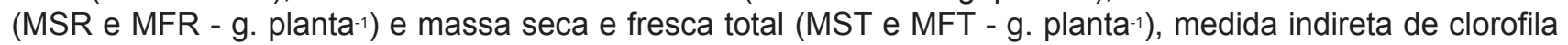
(índice SPAD), altura de planta (AP - cm), teor de óleo (TEOR - \%), e produtividade de óleo (Kg. ha-1) em Aloysia triphylla cultivada em ambiente protegido. Frederico Westphalen - RS, 2012.

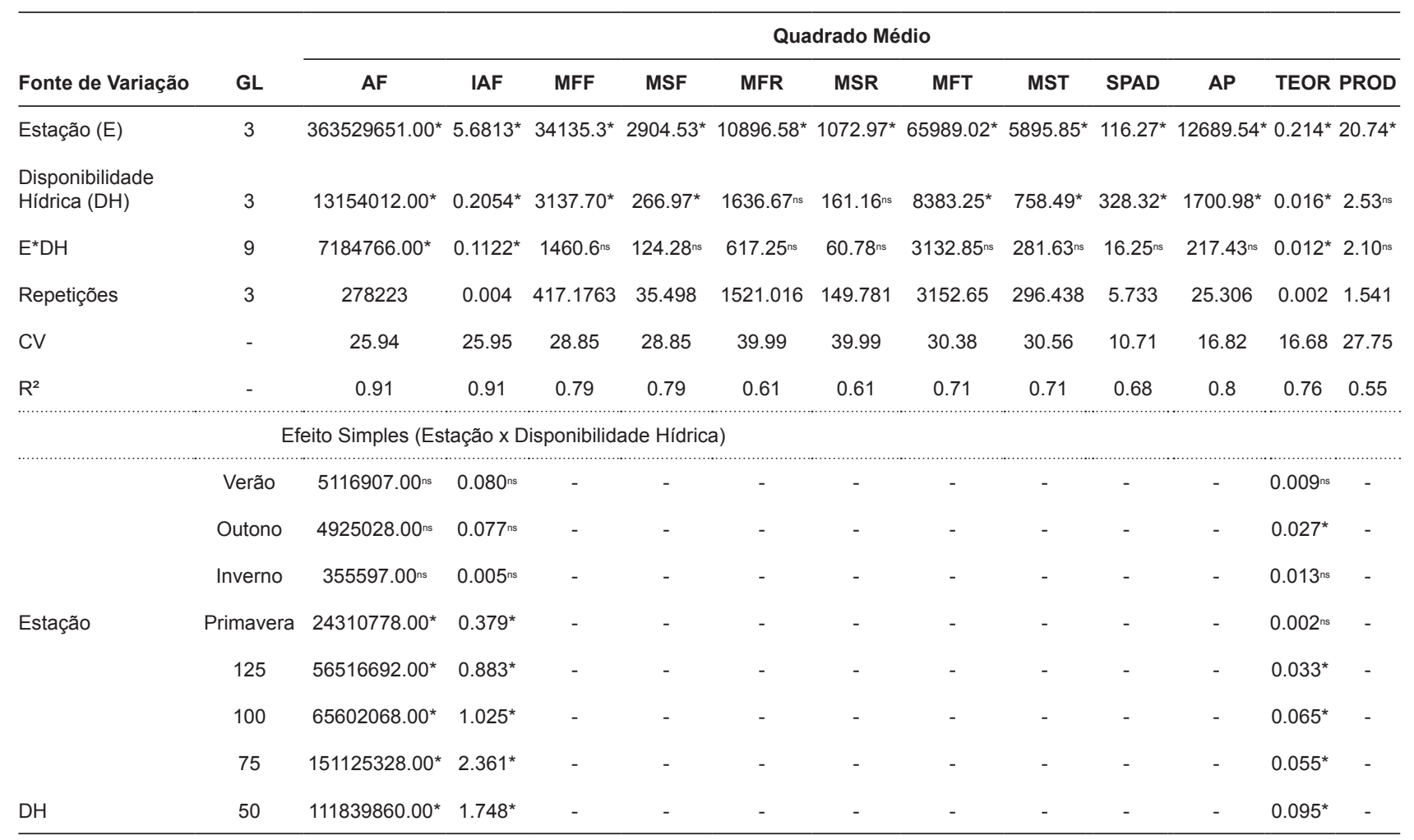

*Significativo e ns não significativo pelo teste $\mathrm{F}$ a $5 \%$ de probabilidade de erro.

Rev. Bras. PI. Med., Campinas, v.17, n.4, p.631-641, 2015. 
nas reposições de 100 e $75 \%$. Na disponibilidade de $50 \%$, a estação verão deteve a menor AF e IAF seguida do inverno.

Desta forma, é possível observar uma forte influência da disponibilidade hídrica na estação de maior demanda de água, ou seja, o verão, onde a reposição de uma lâmina diária de $3.35 \mathrm{~mm}$ (50\% ETo) resultou em uma redução de quase $50 \%$ na produção de biomassa quando comparada à lâmina de irrigação de 7.56 mm. dia-1 (125\% ETo) (Tabela 5). A resposta mais proeminente das plantas ao déficit hídrico, segundo Mccree \& Fernández (1989); Taiz \& Zeiger (1991) consiste no decréscimo da produção da área foliar e no IAF, consequentemente promovendo a aceleração da senescência e da abscisão das folhas. Quando as plantas são expostas a situações de déficit hídrico estas exibem, frequentemente, respostas fisiológicas que resultam

TABELA 5. Efeito da sazonalidade na área foliar ( $A F-\mathrm{cm}^{2}$. planta-1), índice de área foliar $\left(\mathrm{IAF}-\mathrm{m}^{2} . \mathrm{m}^{-2}\right)$, massa

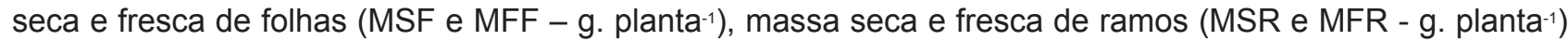
e total (MST e MFT - g. planta-1), medida indireta de clorofila (índice SPAD), altura de planta (AP - $\mathrm{cm}$ ), teor de óleo (TEOR - \%), e produtividade de óleo (Kg. ha-1) em Aloysia triphylla cultivada em ambiente protegido. Frederico Westphalen - RS, 2012.

\begin{tabular}{|c|c|c|c|c|c|c|c|c|c|c|c|c|}
\hline Estação & $A F^{*}$ & $\mathrm{AF}$ & MFF & MSF & MFR & ISR & MFT & MST & SPAD & AP & TEOR & PROD \\
\hline & & $0,45^{\mathrm{bc}}$ & & & & & & & & & $D^{a}$ & $70^{b}$ \\
\hline Out & 4 & $0,57^{b}$ & $104,09^{b}$ & $30,36^{b}$ & $70,55^{a}$ & ta & $174,64 \mathrm{~b}$ & $0^{\circ}$ & 7 a & $b$ & ,38 & $4,62^{b}$ \\
\hline Inverno & 200 & , & , & , & & 0,0 & 0 & & & & Sa & $3,26^{c}$ \\
\hline navera & $3110,40^{a}$ & $1,64^{a}$ & $155,01^{a}$ & $45,22^{a}$ & $77,3 \mathrm{~s}$ & $24,28^{a}$ & 232,4 & $69,50^{a}$ & 34 & 122 & $0,32^{b}$ & 6,05 \\
\hline
\end{tabular}

${ }^{*}$ letras iguais na coluna não diferem entre si a $5 \%$ de probabilidade de erro pelo teste de Tukey.

TABELA 6. Efeito da sazonalidade e diferentes níveis de disponibilidade hídrica nas variáveis área foliar AF $\mathrm{cm}^{2}$. planta-1), índice de área foliar (IAF - $\mathrm{m}^{2} . \mathrm{m}^{-2}$ ) e teor de óleo (TEOR - \%), em Aloysia triphylla cultivada em ambiente protegido. Frederico Westphalen - RS, 2012.

\begin{tabular}{|c|c|c|c|c|}
\hline \multirow{2}{*}{ Época } & \multicolumn{4}{|c|}{ Disponibilidade Hídrica (\% ETo) } \\
\hline & 125 & 100 & 75 & 50 \\
\hline \multicolumn{5}{|c|}{ Área Foliar - AF } \\
\hline Inverno & $2574,236^{\circ}$ & $2820,247^{b}$ & $2877,750^{\circ}$ & 3292,469 bc \\
\hline Outono & $5682,064^{b}$ & $3756,121^{\mathrm{b}}$ & $3507,335^{\mathrm{b}}$ & $5386,147^{\mathrm{b}}$ \\
\hline Primavera & $14640,528^{a}$ & $15774,375^{a}$ & $11008,518^{a}$ & 11018,244 \\
\hline Verão & $4954,665^{b}$ & $3992,037^{b}$ & $2475,810^{b}$ & $2831,635^{\circ}$ \\
\hline \multicolumn{5}{|c|}{ Índice de Área foliar - IAF } \\
\hline Inverno & $0,322^{c}$ & $0,352^{b}$ & 0,359 & $0,411 \mathrm{bc}$ \\
\hline Outono & $0,710^{b}$ & $0,4695^{b}$ & $0,438^{b}$ & $0,673^{b}$ \\
\hline Primavera & 1,830 a & $1,972^{\mathrm{a}}$ & $1,376^{a}$ & $1,377^{a}$ \\
\hline Verão & $0,619 b$ & $0,499 b$ & $0,309 b$ & 0,354 \\
\hline \multicolumn{5}{|c|}{ Teor de óleo - TEOR } \\
\hline Inverno & $0,597^{a}$ & $0,542^{a}$ & $0,542^{a}$ & $0,461^{\mathrm{ab}}$ \\
\hline Outono & $0,295^{b}$ & $0,370^{b}$ & $0,370^{b}$ & $0,356^{\mathrm{bc}}$ \\
\hline Primavera & $0,291^{\mathrm{b}}$ & $0,312^{b}$ & $0,311^{\circ}$ & $0,347^{\circ}$ \\
\hline Verão & $0,506^{a}$ & $0,539 a$ & 0,539 a & $0,539 a$ \\
\hline
\end{tabular}

*letras iguais na coluna não diferem entre si a $5 \%$ de probabilidade de erro pelo teste de Tukey. 

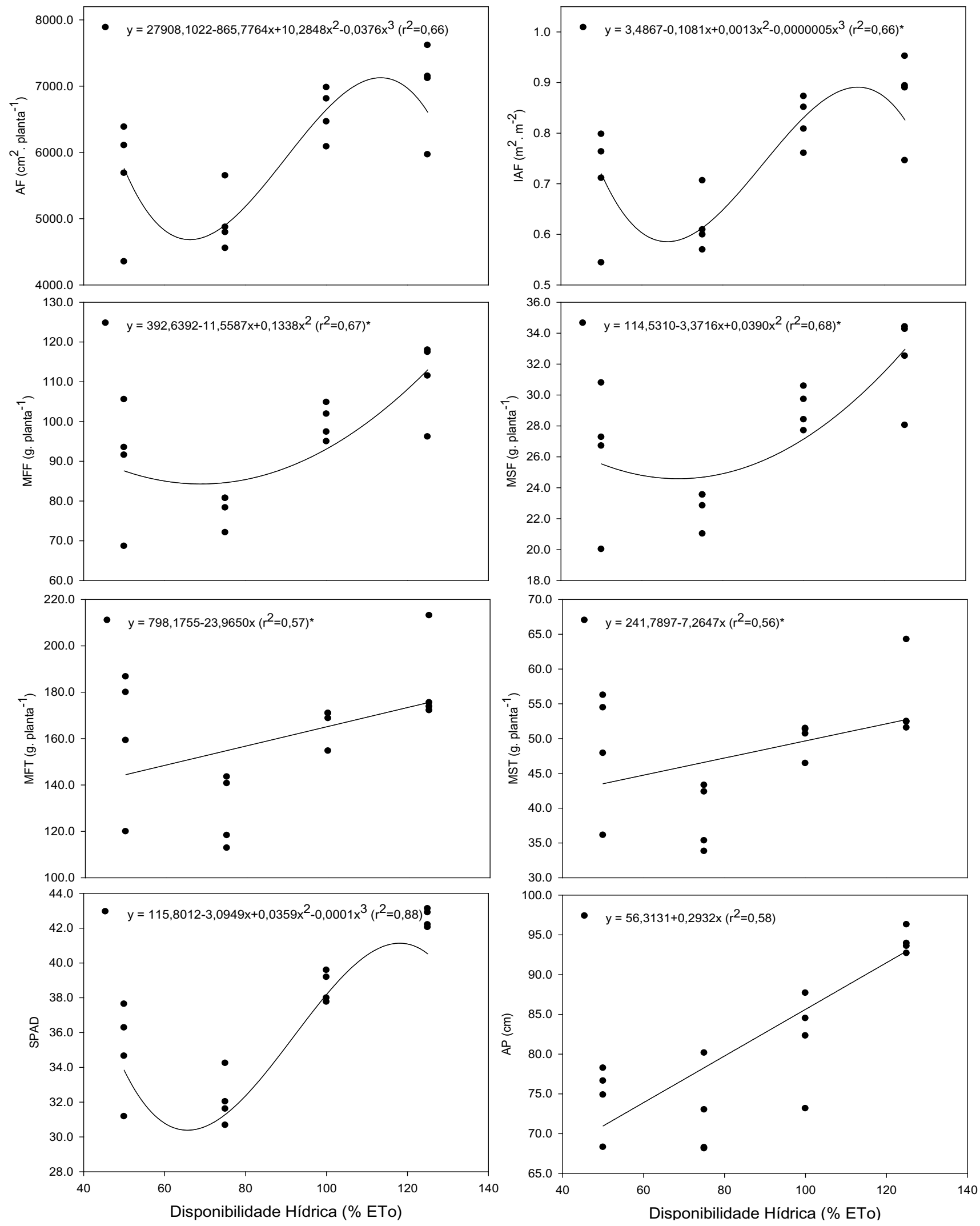

FIGURA 4. Efeito da disponibilidade hídrica nos parâmetros morfológicos, área foliar (AF - $\mathrm{cm}^{2}$. planta-1), índice de área foliar (IAF - $\mathrm{m}^{2} . \mathrm{m}^{-2}$ ), massa seca e fresca de folhas (MSF e MFF - g. planta-1), massa seca e fresca de ramos (MSR e MFR - g. planta-1) e total (MST e MFT - g. planta-1), medida indireta de clorofila (índice SPAD) e altura de planta $(\mathrm{AP}-\mathrm{cm})$, em Aloysia triphylla cultivada em ambiente protegido. Frederico Westphalen - RS, 2012. 


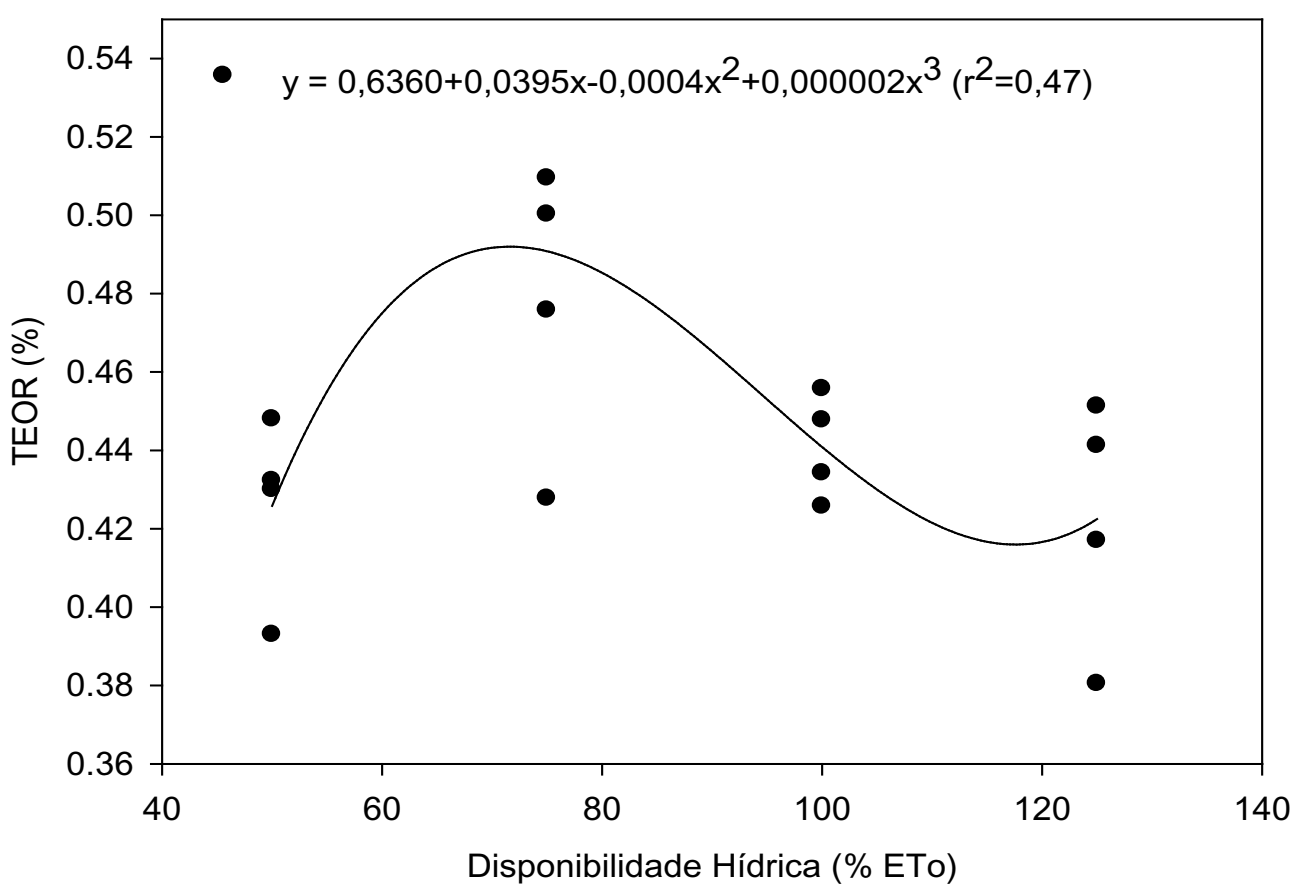

FIGURA 5. Efeito da disponibilidade hídrica sobre o teor de óleo essencial em Aloysia triphylla cultivada em ambiente protegido. Frederico Westphalen - RS, 2012.

de modo indireto, na conservação da água no solo, em vistas a manutenção do seu aparato bioquímico e estrutural, para que assim possa sobreviver a tais condições.

Em espécies medicinais um dos principais componentes avaliados é o teor de óleo essencial presente no tecido foliar. Dessa forma, no presente trabalho observa-se que nas reposições de 125, 100 e $75 \%$ da ETo as coletas realizadas nas estações de inverno e verão apresentaram maior teor de óleo essencial, sendo a primavera responsável pelos menores valores observados. De forma semelhante ao observado no presente trabalho, Botrel et al. (2010), observaram maior teor de óleo essencial em Hyptis marrubioides cultivada na estação do verão.

Os parâmetros fenométricos demonstraram ser influenciados pela disponibilidade hídrica (Figura 4), sendo os maiores valores observados nas disponibilidades hídricas de 100 e $125 \%$ da ETo, concordando com os resultados semelhantes aos obtidos por Silva et al. (2002) em Melaleuca alternifolia. Ao compararmos o desempenho da espécie frente à reposição hídrica (Figura 4), observa-se que reduções de $50 \%$ na disponibilidade de água, ou seja, de 125 para 75 e de 100 para 50 $\%$ da ETo promoveram reduções nas respectivas ordens de 33,45 e 15,60\% para AF; 34,78 e 10,51\% para a MFF; 35,08 e 2,96\% para MFT; 27,92 e
10,05\% para o índice SPAD e 26,11 e $15,28 \%$ para a altura de planta.Assim, é possível inferir que a espécie apresenta respostas positivas ao aumento da reposição hídrica para as variáveis área foliar, índice de área foliar, massa seca e fresca de folhas, massa seca e fresca de ramos, massa fresca e seca total, medida indireta de clorofila (SPAD) e altura de planta. Esse mesmo padrão de resposta positiva da planta à uma maior reposição hídrica também foi observado em trabalhos realizados por Silva et al. (2002) em Melaleuca alternifolia Cheel (Myrtaceae) e Carvalho et al. (2003) em artemísia, onde a deficiência hídrica diminuiu o crescimento e a produção de biomassa fresca e seca das plantas. Marcum \& Hanson (2006) observaram quedas significativas na produção de óleo essencial de menta na Califórnia, quando as plantas foram submetidas a lâminas de irrigação inferiores à evapotranspiração.

O teor de óleo essencial apresenta uma relação inversa com a produção de MFF (Tabela 5), ou seja, quanto maior a produção de folhas, menor o teor nas mesmas, sendo que na primavera ocorreu a maior produção de folhas e o menor teor de óleo, ao passo que na verão e inverno ocorreram as menores produções de folhas e o maior rendimento.

Tal fato pode ser justificado pela ideia proposta por Santos \& Carlesso, (1998), já que os mesmos 
consideram que o déficit hídrico ocasiona mudanças na partição dos carboidratos no interior da planta, condicionando as plantas a desenvolverem mecanismos de adaptação e resistência.

É possível concluir, que para as condições ocorridas no presente trabalho, a disponibilidade hídrica não afetou a produção de óleo por unidade de área, devido à compensação ocorrida pelo maior teor de óleo na biomassa, desta forma, minimizando possíveis efeitos negativos de um cenário com menor disponibilidade hídrica.

Os resultados aqui observados corroboram com os resultados obtidos por Pitarevic et al. (1984) que ao aplicar um longo período de seca em populações naturais de sálvia, observou uma produção elevada de óleo essencial. Também Gouinguené \& Turlings (2002) ao testar diferentes teores de umidade do solo e umidade do ar na emissão de produtos voláteis em plantas jovens do milho observaram uma liberação maior quando as plantas foram conduzidas em solo seco.

Segundo Velloso (2009) e Bray (1993) a resposta das plantas aos estresses ambientais se dá em função da produção de ácido abscísico, o qual desencadeia os processos de redução da área foliar, fotossíntese, transpiração. Sendo o óleo essencial um monoterpeno, contendo apenas uma cadeia de 5 carbonos a menos que o ABA, é possível concluir que a condução de Aloysia triphylla em condições de disponibilidade hídrica reduzida proporciona aumento do teor de óleo essencial no tecido vegetal, sendo essa a resposta positiva desta espécie ao estresse.

Neste contexto, pode-se concluir que:

A sazonalidade causa grande efeito sobre os parâmetros fenométricos, sendo a primavera a estação de maior crescimento, produção de biomassa e rendimento de óleo essencial em Aloysia triphylla.

As estações de verão e inverno apresentam biomassa com maior teor de óleo essencial. Ao passo que a disponibilidade hídrica que proporcionou maior teor de óleo essencial foi a de 75 e 50 \% da evapotranspiração de referência para o ambiente externo.

Reduções na disponibilidade hídrica acarretam menor produção de biomassa, área foliar, medida indireta da clorofila (SPAD) e altura de planta.

\section{REFERÊNCIAS}

ABREU, I.N.; MAZZAFERA, P. Effect of water and temperature stress on the content of active constituents of Hypericum brasiliense Choisy. Plant Physiology and Biochemistry, v.43, n.3, p.241-248, 2005.
ALVARENGA, I. C. A. et al. Response of Lippia sidoides to different irrigation depths." Pesquisa Agropecuária Tropical. v. 42, n. 4, p 462-468, 2012.

ALLEN, R. G. et al. Crop evapotranspiration: guidelines for computing crop water requirements. 1. ed. Rome: FAO, 1998. 300p.

BOTREL, P. P. et al. Teor e composição química do óleo essencial de Hyptis marrubioides EpL. Lamiaceae em função da sazonalidade. Acta Scientiarum. Agronomy, v. 32, n. 3, p. 533-538, 2010.

BRAY, E.A. Molecular responses to water deficit. Plant Physiology v.103, p.1035- 1040. 1993.

CARVALHO, L. M. et al. Disponibilidade de água no solo e crescimento de artemísia. Horticultura brasileira, v. 21, n. 4, p. 726-730, 2003.

EMBRAPA - EMPRESA BRASILEIRA DE PESQUISA AGROPECUÁRIA. Sistema Brasileiro de Classificação de Solos. 2 ed. Rio de Janeiro : EMBRAPA-SPI, 2006, 412 p.

GOUINGUENÉ, S. P.; TURLINGS, T. C. J. The effects of abiotic factors on induced volatile emissions in corn plants. Plant Physiology. v.129, p. 1296-1307, 2002.

HARTMANN, T. Global harmonization of herbal health claims Entomologia Experimentalis et Applicata v. 80, p. 177-179, 1996.

KRAMER, P. J.; BOYER, J. S. Water relations of plants and soils. San Diego: Academic, 495p, 1995.

KUTCHAN, T. M. Herbal mixtures in the traditional medicine of Eastern Cuba. Plant Physiology v. 125, p. 58-62. 2001.

LINDROTH, R. L. et al. Tropical Plants. Biochemical Systematics and Ecology. v.15, p.681-682, 1987.

LORENZI, H.; MATOS, F.J.A. Plantas medicinais no Brasil: nativas e exóticas cultivadas. 2.ed. Nova Odessa: Plantarum, 486p, 2008.

MALUF, J. R. T. Nova classificação climática do Estado do Rio Grande do Sul. Revista Brasileira de Agrometeorologia, v. 8, n. 1, p. 141-150, 2000.

MARCUM, D.B.; HANSON, B.R. Effect of irrigation and harvest timing on peppermint oil yield in California. Agricultural Water Management, v.82, n.1- 2, p.118128, 2006.

MCCREE, K. J.; FERNÁNDEZ, C. J. Simulation model for studyng physiological water stress responses of whole plants. Crop Science, v.29, p.353-360, 1989.

MEIRA, M.R. et al. Crescimento e produção de óleo essencial de Melissa officinalis L. nas condições climáticas de Montes Claros - MG. Biotemas, v.24, n.1, p.1-8, 2011.

MINOLTA CAMERA Co., Ltda. Manual for chlorophyll meter SPAD 502. Osaka: Minolta, Radiometric Instruments Divisions, p.22, 1989.

PAULUS, D. et al. Teor e Composição Química do Óleo essencial e Crescimento vegetativo de Aloysia triphylla em diferentes espaçamentos e épocas de Colheita. Revista Ceres ,v. 60, n 3, p. 372-379, 2013.

PINTO, J. E. B. P.; BERTOLUCCI, S. K. V. Cultivo e processamento de plantas medicinais. Lavras: UFLA, p.47, 2002.

PITAREVIC, I. et al. Seasonal variation of essential oil yield and composition of dalmatian sage, Salvia officinalis. Journal of Natural Products. v.47, n.3, p.409-412, 1984. 
PRAVUSCHI, P.R. et al. Efeito de diferentes laminas de irrigação na produção de óleo essencial do manjericão (Ocimum basilicum L.). Acta Scientiarum Agronomy, v.32, n.4, p.687-693, 2010.

RODRIGUES-DAS-DORES, R.G.; CASALI, V. W. D. Plantas Medicinais e Aromáticas: Controle de Qualidade de Fitoterápicos. 1. ed. Ponte Nova: D\&M gráfica, 160 p, 2007.

SANTOS, R. F.; CARLESSO R. Déficit hídrico e os processos morfológico e Fisiológico das plantas. Revista Brasileira de Engenharia Agrícola e Ambiental, v.2, n.3, p.287-294, 1998.

SAS LEARNING EDITION. Getting started with the SAS Learning Edition. Cary, 200p, 2003.

SILVA, R. Crescimento e teor de óleo essencial de Aloysia triphylla (L'Hérit) Britton (Verbenaceae), em função da adubação orgânica, sazonalidade, horário de colheita e processamento póscolheita. 2005. 66f. Dissertação (Mestrado em
Fitotecnia) Universidade Federal de Lavras, Lavras, 2005.

SILVA, S. R. S. et al. Efeito do estresse hídrico sobre características de crescimento e a produção de óleo essencial de Melaleuca alternifolia Cheel. Acta Scientiarum Agronomy. v. 24, n. 5, p. 1363-1368, 2002.

TAIZ, L.; ZEIGER, E. Plant Physiology. California: The Benjamim/ Cummings Publishing Company, Inc., Redwood City, 1991.

TURNER, N. C.; JONES, M. M. Turgor maintenance by osmotic adjustment: a review and evaluation. In: Adaptation of plants to water and high temperature stress. Turner, N. C. e Kramer, P. J. (Ed.) Wiley Publ., New York. p. 87-103, 1980.

VELLOSO, M. A. L. et al. Indução de metabólitos secundários em plântulas de Hypericum brasiliense Choisy crescendo in vitro. Acta Amazônica v. 39, n 2, p. 267-272, 2009. 